\title{
Synthesis of Volatile, Reactive Coinage Metal 5,5-Bicyclic Amidinates With Enhanced Thermal Stability for Chemical Vapor Deposition
}

\section{Citation}

Tong, L., L. Davis, X. Gong, J. Feng, E. Beh, and R. Gordon. 2019. Synthesis of Volatile, Reactive Coinage Metal 5,5-Bicyclic Amidinates With Enhanced Thermal Stability for Chemical Vapor Deposition. Dalton Transactions 48, no. 20: 6709-6713.

\section{Permanent link}

http://nrs.harvard.edu/urn-3:HUL.InstRepos:42482313

\section{Terms of Use}

This article was downloaded from Harvard University's DASH repository, and is made available under the terms and conditions applicable to Open Access Policy Articles, as set forth at http:// nrs.harvard.edu/urn-3:HUL.InstRepos:dash.current.terms-of-use\#OAP

\section{Share Your Story}

The Harvard community has made this article openly available. Please share how this access benefits you. Submit a story. 


\title{
Synthesis of Volatile, Reactive Coinage Metal 5,5-Bicyclic Amidinates with Enhanced Thermal Stability for Chemical Vapor Deposition $\dagger$
}

\author{
Liuchuan Tong, ${ }^{a}$ Luke M. Davis, ${ }^{\mathrm{a},}{ }^{\S}$ Xian Gong, ${ }^{\mathrm{b}}$ Jun Feng, ${ }^{a}{ }^{\|}$Eugene S. Beh, ${ }^{\mathrm{a},{ }^{\ddagger}}$ and Roy G. Gordon*a,b
}

\begin{abstract}
Many microelectronic devices require thin films of silver or gold as wiring layers. We report silver(I) and gold(I) bicyclic amidinate complexes, wherein the constrained ligand geometry lessens the propensity for thermal decomposition. These new volatile compounds provide metallic films of silver and gold during CVD with hydrogen below $230^{\circ} \mathrm{C}$.
\end{abstract}

As microelectronic device features shrink and new, threedimensional architectures are adopted, the demand grows for new methods to coat and fill these narrow or enclosed features. Chemical vapor deposition (CVD) and atomic layer deposition (ALD) are routinely used in the semiconductor industry for depositing conformal thin films in features with high aspect ratios. ${ }^{1-4}$ The key to the success of new CVD and ALD processes is the development of volatile, thermally stable, yet highly reactive metal precursors. ${ }^{5,6}$ Gold and silver are particularly important contact metals in a variety of circuits.

Even though copper can be deposited from a number of CVD precursors, ${ }^{7-14}$ relatively few gold and silver CVD precursors are known. ${ }^{15-20}$ Whereas alkyl-substituted amidinate ligands stabilize and volatilize many metal CVD and ALD precursors, ${ }^{10}$, 11, 21-23 silver and gold amidinates with alkyl substituents can be difficult to prepare and tend to decompose during sublimation or upon exposure to light, 11, 24, 25 which can limit their application in vapor deposition. Several aryl-substituted amidinates of silver(I) and gold(I) are known, ${ }^{26-30}$ but compounds with aryl substituents rarely have high volatility.

One common explanation for thermal instability in coinage metal alkylamidinates is the migration of a $\beta$-hydrogen to the metal, cleaving the metal-nitrogen bond and forming an unstable metal hydride. Amidinates lacking $\beta$-hydrogens and having cyclic backbones have been employed to suppress this decomposition pathway. ${ }^{25}$ 31, 32 Barry and coworkers prepared silver(I) and gold(I) tert-butylimino-2,2-dimethylpyrrolidinates, combining these strategies and improving thermal stability to $170{ }^{\circ} \mathrm{C} .{ }^{25}$ Silver and gold films can be grown with these singlesource CVD precursors via thermolysis; ${ }^{25}$ however, the gold films are carbon-contaminated and poorly conductive $(\rho=5580$ $\mu \Omega \cdot \mathrm{cm}, c f .2 .44 \mu \Omega \cdot \mathrm{cm}$ for bulk gold). The tert-butyl group in the

\footnotetext{
a. Department of Chemistry and Chemical Biology, Harvard University, Cambridge MA 02138, USA

b. Harvard John A. Paulson School of Engineering and Applied Sciences, Harvard University, Cambridge, MA 02138, USA

present address: Department of Chemistry, Tufts University, 62 Talbot Avenue, Medford, Massachusetts 02155, USA

present address: Applied Materials Inc., 1140 E Arques Ave, Sunnyvale, CA 94085, USA

present address: Palo Alto Research Center, 3333 Coyote Hill Road, Palo Alto, CA 94304, USA

$\dagger$ Electronic Supplementary Information (ESI) available: full experimental details and spectra. CCDC 1888869-1888870 contain the supplementary crystallographic data for this paper. See DOI: $10.1039 / x 0 x x 00000 x$
}

ligand may undergo $\beta$-methyl migration to gold, providing an easily accessed carbon source.

We have recently reported the synthesis of the purposedesigned, fully $\beta$-substituted 5,5-bicyclic amidine ligand $\mathbf{1}$, and its copper (I) complex (Scheme 1).32 The lack of $\beta$-hydrogens prevents $\beta$-hydride elimination, and the bicyclic system constrains bond rotations to make $\beta$-methyl migration reactions unlikely. ${ }^{32}$ Consistent with this goal, the solution thermal decomposition rate of $\mathbf{2},{ }^{32}$ a dimeric copper(I) complex of $\mathbf{1}$, is $10 \times$ slower than that of a previously reported ${ }^{11}$ acyclic copper(I) amidinate. Encouraged by this result, we investigated the ability of bicyclic 1 to form volatile gold and silver CVD compounds. Herein we report the synthesis of volatile gold(I) and silver(I) complexes of $\mathbf{1}$, and demonstrate their use in CVD of gold and silver thin films.

The synthesis of the gold(I) complex $\mathbf{3}$ is analogous to the synthesis of the copper(I) complex 2 (Scheme 1). ${ }^{32}$ Although $\mathrm{AuCl}$ can be used to prepare 3 , its more soluble dimethylsulfide adduct, $\mathrm{AuCl}\left(\mathrm{SMe}_{2}\right),{ }^{33}$ provides improved yields. Treatment of a THF solution of 1 with KHMDS, followed by transmetalation with $\mathrm{AuCl}\left(\mathrm{SMe}_{2}\right)$, affords the gold(I) amidinate complex 3 . During the reaction, the suspension turns purple, indicating the formation of $\mathrm{Au}^{0}$ nanoparticles as a side product. Filtration of the purple suspension gives a clear solution, which affords white 3 in 60\% yield upon concentration, and $\mathbf{3}$ may be further purified by recrystallization from $\mathrm{CH}_{2} \mathrm{Cl}_{2}$ or by sublimation at $170{ }^{\circ} \mathrm{C}$ and 30 mTorr. Compound 3 is poorly soluble in THF, requiring large amounts of THF to ensure all product dissolves during filtration. Importantly, $\mathbf{3}$ does not decompose for several

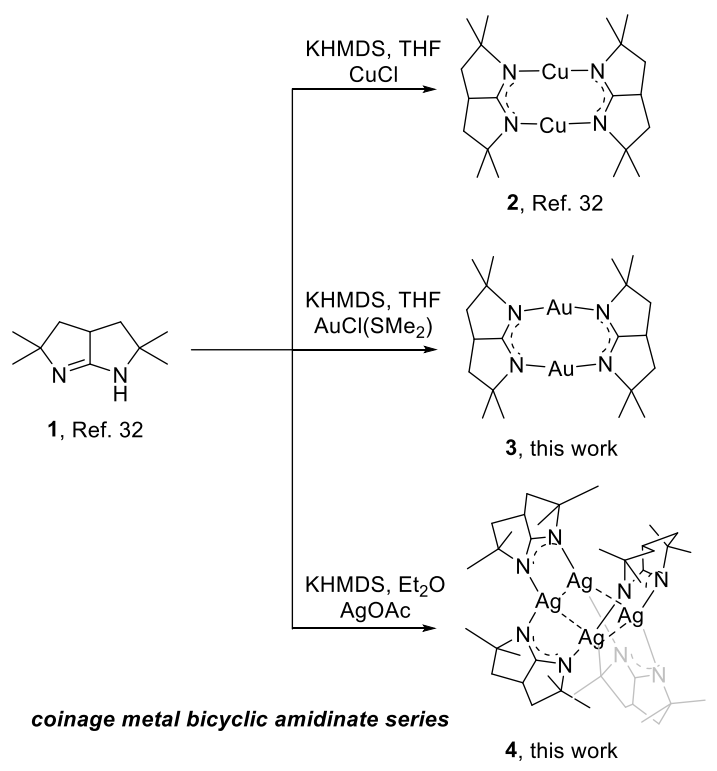

Scheme 1. Synthetic routes to complexes $\mathbf{2}, \mathbf{3}$, and $\mathbf{4}$. 
weeks in air, and therefore the purification steps can be carried out in air without loss of yield.

The ${ }^{1} \mathrm{H}$ NMR spectrum of $\mathbf{3}$ is similar to that of $\mathbf{2}$ (Figure S13 ). As in 2, splitting of the methyl groups appears to indicate the presence of two diastereomers.

Single-crystal X-ray diffraction confirmed that the gold(I) complex 3 possesses the same solid-state dimeric structure as the copper(I) complex 2 (Figure 1a and Tables S1,2,4,6). Gold(I) amidinates and guanidinates typically adopt dimeric ${ }^{24,30,34}$ or tetrameric structures, ${ }^{35-38}$ depending on the steric demand of the ligand. One of these tetramers is a gold(I) complex of 1,4,6triazabicyclo[3.3.0]oct-4-ene, ${ }^{35}$ the non-methylated guanidine analogue of $\mathbf{1}$, suggesting that in $\mathbf{3}$ the four methyl groups per ligand may contribute to the preference for a dimeric structure.

The gold atoms and the amidinate $\mathrm{N}-\mathrm{C}-\mathrm{N}$ cores form a single plane, with symmetric Au-N distances of 2.013(3) $\AA$ that fall on the short end of typical gold(I) amidinates. ${ }^{24,30,34-39}$ The $\mathrm{Au} \cdots \mathrm{Au}$ distance of 2.855(1) $\AA$ is long for a digold(I) amidinate, in which this distance is typically 2.644(2)-2.711(3) A. 24, 30, 34, 39 The ringconstrained $\mathrm{N}-\mathrm{C}-\mathrm{N}$ angle is also larger than usual, at $131.9(2)^{\circ}$ (cf. 121.8(5)-128.6(5) ${ }^{\circ}$ in gold(I) amidinates). ${ }^{24,30,34-39}$

Interestingly, molecules of $\mathbf{3}$ pack face-to-edge (Figures $1 \mathrm{~b}$, S7 and Table S6), with three neighboring methyl groups pointing at each planar face of the molecule. A recent review of $\mathrm{Au} \cdots \mathrm{H}-\mathrm{C}$ interactions describes as hydrogen bonding $\mathrm{Au}^{\mathrm{l}} \cdot \ldots \mathrm{H}-\mathrm{C}$ distances $A u^{1} \cdots H<3 \AA$ and $A u^{1} \cdots C<4 \AA$, preferably with the $A u^{1} \cdots H-C$ angle approaching $180^{\circ} .{ }^{40}$ Two of the three methyl groups meet this definition, and the third is just $0.2 \AA$ longer. Thus, each molecule has two or three weak gold(I)-methyl contacts on each face, which may stabilize the solid-state packing of 3 .

Synthesis of the silver(I) analogue $\mathbf{4}$ presented more challenges than the gold and copper counterparts. Despite previous efforts often employing $\mathrm{AgCl}$ to synthesize silver amidinate compounds, 11,25 the reaction of $\mathrm{AgCl}$ with the deprotonated form of $\mathbf{1}$ was incomplete after several days of stirring, likely owing to the low solubility of $\mathrm{AgCl}$.

After some screening, AgOAc was selected as the silver(I) source since it has higher solubility in organic solvents. Treatment of a solution of $\mathbf{1}$ in diethyl ether with KHMDS, followed by transmetalation with AgOAc, gave the silver(I) complex 4. Filtration of the brown suspension, presumably colored by some $\mathrm{Ag}^{0}$ nanoparticles, gave a clear brown solution. Compound 4 was obtained as white solids in $45 \%$ yield upon a

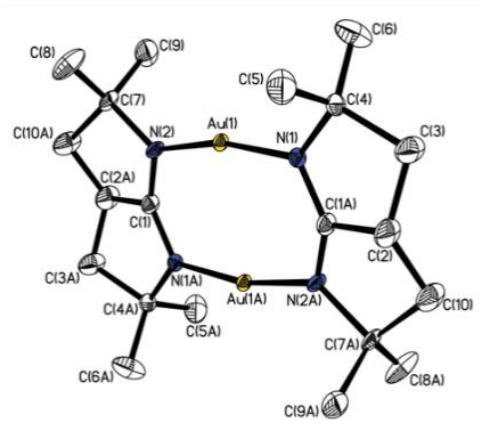

b

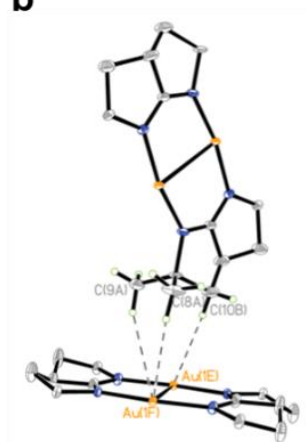

Fig 1. a) Solid-state structure of $\mathbf{3}$ with $50 \%$ probability thermal ellipsoids; hydrogen atoms are omitted for clarity. Selected distances $(\AA)$ and angles $\left({ }^{\circ}\right)$ : Au$\mathrm{N} 2.013(3), \mathrm{Au}(1) \cdots \mathrm{Au}(1 \mathrm{~A})$ 2.855(1); N(1)-Au(1)-N(2) 167.4(1). b) Gold(I)-methyl interactions between two neighboring molecules. Metrics are given in Table S6. concentration of this liquor. Similar to $\mathbf{3}$, the silver(I) amidinate 4 is stable in air for several weeks.

The ${ }^{1} \mathrm{H}$ NMR spectrum of 4 contains many more peaks than the spectrum of $\mathbf{2}$ or $\mathbf{3}$ (Figure S4-5). Microanalysis indicated the correct stoichiometry, though, and the product NMR spectrum remained unchanged after sublimation at $160^{\circ} \mathrm{C}$ and 30 mTorr.

Consistent with these data, single-crystal X-ray diffraction revealed compound 4 to be the authentic silver(I) complex, but having a tetrameric structure (Figure $2 a$ and Tables S1,3,5) instead of sharing the dimeric structures of $\mathbf{2}$ and $\mathbf{3}$. Although silver(I) amidinates are usually dimers ${ }^{11,26,27,34,41}$ or trimers, ${ }^{11}$, 24 tetrameric amidinates ${ }^{28}$ and a guanidinate ${ }^{42}$ are known.

The tetranuclear silver(I) core of $\mathbf{4}$ forms a rhombus, with sides 3.296(2) $\AA$ and diagonal 3.096(2) $\AA$ ( $\mathrm{Ag}(1) \cdots \mathrm{Ag}(1 \mathrm{~A}))$; these side distances are longer than the distances of $2.807(1)-2.920(1)$ Å found in related tetramers. ${ }^{28,} 42$ The ligands bridge between silver atoms, in an alternating up-down-up-down fashion around the ring. As in 3, the Ag-N distances in 4, 2.054(2) and 2.094(2) $\AA$, are among the shorter distances found in tetrasilver(I) amidinates, 2.076(4)-2.140(4) Å. ${ }^{28,} 42$ Constrained by its 5,5 -bicycle, the amidinate $\mathrm{N}-\mathrm{C}-\mathrm{N}$ angle is unusually large: $131.9(2)^{\circ}$, vs. typical values of $119.0(7)^{\circ}-125.6(2)^{\circ} .11,24,34,42$

The best structural model of $\mathbf{4}$ has a disorder component that refines to represent $25 \%$ of the ligands (Figure $2 \mathrm{~b}$ ). This $25 \%$ has the conformation with the methine hydrogen pointing away from the $\mathrm{Ag}_{4}$ core. The combination of the tetrameric structure and multiple stereoisomers presumably gives rise to the more complicated NMR spectrum of 4 .

Thermogravimetric analysis (TGA) was performed in a nitrogen-filled glovebox to study the thermal stability and evaporation rate of 2-4 (Figure 3). As reported previously, 32 sublimes cleanly under a linear temperature ramp, with $50 \%$ mass loss at $270{ }^{\circ} \mathrm{C}$ and $<0.2 \mathrm{wt}$. \% of residue. In contrast, the gold(I) compound $\mathbf{3}$ had two weight loss regions overlapping each other, with the second starting at around $310^{\circ} \mathrm{C}$. After heating to $500{ }^{\circ} \mathrm{C}, \sim 25$ wt. \% remained, along with a purple residue on the TGA pan. Presumably this material is gold nanoparticles generated by thermolysis of $\mathbf{3}$, which begins at a higher temperature than the sublimation onset. More surprising was the TGA of silver(I) compound 4. Although the silver compound exists as a tetramer in the solid state, $\mathbf{4}$ had a mass loss profile similar to that of $\mathbf{2}$, except with ca. $12 \mathrm{wt}$ \%

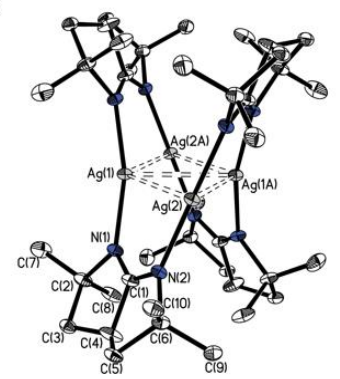

b

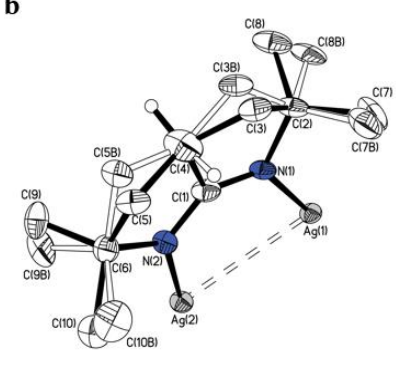

Fig 2. a) Solid-state structure of 4 with $50 \%$ probability thermal ellipsoids. Hydrogen atoms and minor disorder component $(25 \%)$ are omitted for clarity. Selected distances $(\AA ̊)$ and angles $\left({ }^{\circ}\right)$ : $\mathrm{Ag}(1)-\mathrm{N}(1)$ 2.094(2), $\mathrm{Ag}(2)-\mathrm{N}(2)$ 2.054(2); $\mathrm{N}(1)-\mathrm{Ag}(1)-$ $\mathrm{N}(1 \mathrm{~A}) 165.5(1), \mathrm{N}(2)-\mathrm{Ag}(2)-\mathrm{N}(2 \mathrm{~A}) 178.0(1)$. b) View of the asymmetric unit, with both disorder components shown; closed (black) bonds indicate the major component (75\%), and open (white) bonds indicate the minor component (25\%). The $35 \%$ thermal ellipsoids are shown, with hydrogen atoms omitted for clarity. 
residue. It is hypothesized that the tetrameric silver(I) compound may rearrange to a dimer upon heating, resulting in evaporation kinetics in line with dimeric $\mathbf{2}$ and $\mathbf{3}$ (Figure S6).

CVD precursors should sublime without decomposition in the CVD sublimation chamber. Clear evidence of degradation in the ramp TGA curves made it difficult to judge whether there would be sublimation-only regions for 3 and $\mathbf{4}$. Therefore, we conducted isothermal TGA experiments at temperatures between 180 and $240{ }^{\circ} \mathrm{C}$. The resulting evaporation rates were plotted on a log-reciprocal plot, Figure $3 b$; linearity on this plot confirms a single mass-loss mechanism in the studied temperature range. Making the usual assumption about constant surface area, effective enthalpies of sublimation can be extracted from these plots. Compound $\mathbf{2}$ has an enthalpy of sublimation of $109 \mathrm{~kJ} / \mathrm{mol}$, as reported earlier; ${ }^{32}$ complexes 3 and 4 have sublimation enthalpies of 140 and $122 \mathrm{~kJ} / \mathrm{mol}$, respectively. Especially given that metal-nitrogen bond lengths are typically shorter in gold(I) than in silver(I) complexes of the same amidinate ligand, $11,24,26,30,34,35,39,42$ and therefore the gold molecules are smaller, it is tempting to propose that the gold(I)-methyl interactions described above contribute to the higher sublimation enthalpy of $\mathbf{3}$ compared with $\mathbf{4}$.

With new, sublimable silver(I) and gold(I) compounds in hand, we sought to evaluate their suitability as CVD precursors. Silver and gold metal films were deposited in a custom-built CVD system (Scheme S1), using precursor vapor carried by nitrogen or argon and molecular hydrogen as the reductant. During the deposition process, the vaporized precursor was carried with a constant flow of $100 \mathrm{sccm}$ of inert gas, and then mixed with purified hydrogen gas before reaching the preheated reaction chamber. The temperature of the precursor was maintained at various values from 160 to $180{ }^{\circ} \mathrm{C}$ for both silver and gold depositions. Substrate temperatures of 200-230 ${ }^{\circ} \mathrm{C}$ were explored for both silver and gold depositions.

Figure $4 a, b$ shows the cross-sectional and plan-view scanning electron micrographs of gold and silver films deposited from $\mathbf{3}$ and $\mathbf{4}$ in the presence of $\mathrm{H}_{2}$. Small crystalline grains were observed in both gold and silver films. Film thickness was measured in the cross-sectional images, and the effective growth rate extracted using the CVD reaction time (Table $S 7,8$ ).

Film composition and purity were determined using X-ray photoelectron spectroscopy (XPS). Survey scans of gold and silver films are shown in Figure 4c,d; gold and silver are the primary components. Fine scans of the $\mathrm{C} 1 \mathrm{~s}$ region (Figure $\mathrm{S} 8$ ), reveal 5.9 at. \% and 6.6 at. \% of carbon in gold and silver films, a

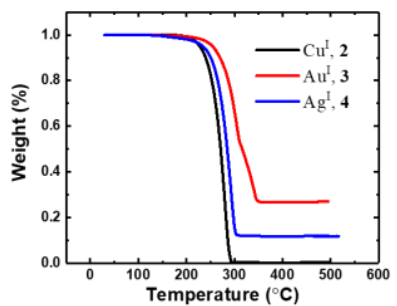

b

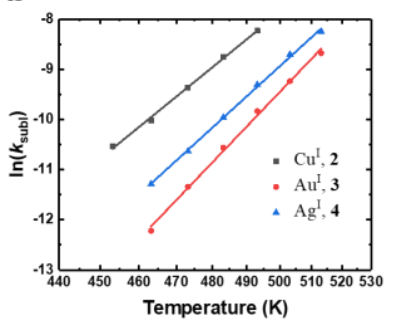

Fig 3. a) Ramp TGA of compounds 2,3 , and 4 . A linear ramp of $10^{\circ} \mathrm{C} / \mathrm{min}$ was used with a sample mass of ca. $10 \mathrm{mg}$. b) Arrhenius plot of stepped-isothermal TGA. Each temperature was held for $11 \mathrm{~min}$. The temperature is plotted in reciprocal scale. Data for $\mathbf{2}$ adapted from Ref 30.
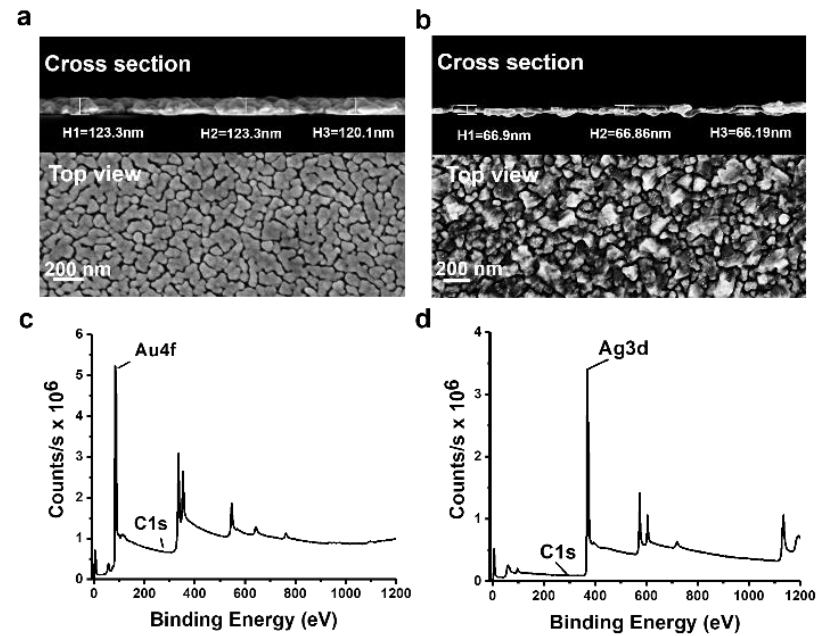

Fig 4. Film characterization; SEM images of a) a gold film, and b) a silver film. XPS survey scans of the optimal film at the deepest etching level for $\mathbf{c}$ ) gold and d) silver.

respectively. No oxygen peaks can be detected in XPS fine scans. Our conditions deposit gold and silver films of good purity.

Gold and silver films both displayed a mirror-like finish (Figure S9a). A positive linear relation was observed between the precursor reservoir temperature and the CVD growth rate for both metals (Figure S9b), presumably resulting from higher evaporation rates providing greater precursor flux. The data show a higher growth rate for silver than for gold at a given reservoir temperature, consistent with the higher enthalpy of sublimation of 3. Given the low, flux-limited growth rates $(<$ $0.26 \mathrm{~nm} / \mathrm{min}$ ), the growth may depend on reactor geometry, and these precursors might benefit from direct liquid evaporation. Alternatively, ligand modifications to reduce solidstate intermolecular interactions might be beneficial.

No gold film was obtained without hydrogen gas as a coreactant, confirming that the pure gold films were produced by hydrogen reduction of $\mathbf{3}$ instead of thermal decomposition. For the silver precursor $\mathbf{4}$, films were obtained even in the absence of molecular hydrogen due to parasitic thermal decomposition of the silver precursor at $230{ }^{\circ} \mathrm{C}$. However, this silver film was $\sim 40$ at. \% carbon by XPS and was not electrically conductive.

Electrical resistivity was measured for both gold and silver films using a four-point probe and a Hall effect measurement system. In the case of gold films, a variety of deposition conditions provided low resistivities, in the range of 22.2-25.1 $\mu \Omega \cdot \mathrm{cm}$ (Table S7); these values are within one order magnitude of bulk gold $(2.44 \mu \Omega \cdot \mathrm{cm})$. The resistivity of silver films ranged from $19.2 \mu \Omega \cdot \mathrm{cm}$ to $220 \mu \Omega \cdot \mathrm{cm}$ (Table S8). The purest silver film has the lowest resistivity, $19.2 \mu \Omega \cdot \mathrm{cm}$, also near an order of magnitude over bulk silver $(1.59 \mu \Omega \cdot \mathrm{cm})$; different carbon impurity levels may drive resistivity differences between CVD conditions.

In summary, volatile homoleptic gold(I) and silver(I) amidinates were synthesized by reactions of metal(I) sources with alkali metal amidinates. The tetrameric silver complex $\mathbf{4}$ is believed to rearrange into a dimer similar to the gold complex $\mathbf{3}$ upon heating. Both $\mathbf{3}$ and $\mathbf{4}$ show remarkable stability to air, light, and heat while retaining reactivity with molecular hydrogen. Metallic gold and silver films were obtained by CVD 
with hydrogen. Films with good purity and conductivity could be obtained at substrate temperatures below $230{ }^{\circ} \mathrm{C}$. Our work illustrates the power of bicyclic amidinate ligands to support reactive and volatile transition metal compounds with enhanced thermal stability relative to previous state-of-the-art ligands, opening up the possibility of further advances in the vapor deposition of challenging-to-deposit metals.

This research was supported by the US National Science Foundation \#1764338, Department of Energy \#DE-AC3608G028308, Office of Naval Research \#N00014-10-0937, Defense Advanced Research Projects Agency \#SC0010000000950 and \#FA8650-15-C-7543, and TEL Technology Center, America LLC \#A33073. Some of the work was performed at Harvard University's Center for Nanoscale Systems (CNS), a member of the National Nanotechnology Infra-Structure Network (NNIN).

\section{Conflicts of interest}

Harvard University has filed a patent application based on the compounds described here.

\section{Notes and references}

1. A. C. Jones and M. L. Hitchman, Chemical Vapour Deposition: Precursors, Processes and Applications RSC Publishing, Cambridge, 2009.

2. S. M. George, Chem. Rev., 2010, 110, 111.

3. R. G. Gordon, in Atomic Layer Deposition for Semiconductors, eds. C. S. Hwang and C. Y. Yoo, Springer US, New York, 2014, pp. 15.

4. R. W. Johnson, A. Hultqvist and S. F. Bent, Mater. Today, 2014, 17, 236

5. M. Putkonen and L. Niinistö, in Precursor Chemistry of Advanced Materials, ed. R. A. Fischer, Springer Berlin Heidelberg, Berlin, Heidelberg, 2005, pp. 125.

6. J. Hämäläinen, M. Ritala and M. Leskelä, Chem. Mater. 2014, 26, 786.

7. T. J. Wenzel, E. J. Williams, R. C. Haltiwanger and R. E. Sievers, Polyhedron, 1985, 4, 369.

8. P. Maårtensson and J. O. Carlsson, J. Electrochem. Soc. 1998, 145, 2926.

9. K.-H. Park and W. J. Marshall, J. Am. Chem. Soc, 2005, 127, 9330

10

Z. Li, S. T. Barry and R. G. Gordon, Inorg. Chem., 2005, 44, 1728.

11. B. S. Lim, A. Rahtu, J.-S. Park and R. G. Gordon, Inorg. Chem., 2003, 42, 7951.

12. J. P. Coyle, W. H. Monillas, G. P. A. Yap and S. T. Barry, Inorg. Chem., 2008, 47, 683.

13. J. W. Park, H. S. Jang, M. Kim, K. Sung, S. S. Lee, T.-M. Chung S. Koo, C. G. Kim and Y. Kim, Inorg. Chem. Commun., 2004 7, 463.

14. V. V. Grushin and W. J. Marshall, Adv. Synth. Catal., 2004, 346, 1457.

15. Z. Yuan, N. H. Dryden, J. J. Vittal and R. J. Puddephatt, Chem. Mater., 1995, 7, 1696.

$16 . \quad$ Z. Yuan, N. H. Dryden, X. Li, J. J. Vittal and R. J. Puddephatt, J. Mater. Chem., 1995, 5, 303

17. K.-M. Chi and Y.-H. Lu, Chem. Vap. Deposition, 2001, 7, 117

18. L. Gao, P. Härter, C. Linsmeier, A. Wiltner, R. Emling and D.
Schmitt-Landsiedel, Microelectron. Eng., 2005, 82, 296.

19. E. Szłyk, P. Piszczek, I. Łakomska, A. Grodzicki, J. Szatkowski and T. Błaszczyk, Chem. Vap. Deposition, 2000, 6, 105.

20. R. G. Parkhomenko, A. E. Turgambaeva, N. B. Morozova, S V. Trubin, V. V. Krisyuk and I. K. Igumenov, Chem. Vap. Deposition, 2013, 19, 38.

21. B. S. Lim, A. Rahtu and R. G. Gordon, Nat. Mater., 2003, 2, 749.

22. O. M. El-Kadri, M. J. Heeg and C. H. Winter, Dalton Trans. 2006, 0, 4506.

23. Z. Li, R. G. Gordon, V. Pallem, H. Li and D. V. Shenai, Chem. Mater., 2010, 22, 3060.

24. T. J. J. Whitehorne, J. P. Coyle, A. Mahmood, W. H. Monillas, G. P. A. Yap and S. T. Barry, Eur. J. Inorg. Chem., 2011, 3240.

25. J. P. Coyle, P. G. Gordon, A. P. Wells, D. J. Mandia, E. R. Sirianni, G. P. A. Yap and S. T. Barry, Chem. Mater., 2013, 25 4566.

26. A. C. Lane, M. V. Vollmer, C. H. Laber, D. Y. Melgarejo, G. M. Chiarella, J. John P. Fackler, X. Yang, G. A. Baker and J. R. Walensky, Inorg. Chem., 2014, 53, 11357.

27. S. J. Archibald, N. W. Alcock, D. H. Busch and D. R. Whitcomb, Inorg. Chem., 1999, 38, 5571.

28. S. J. Archibald, N. W. Alcock, D. H. Busch and D. R. Whitcomb, J. Cluster Sci., 2000, 11, 261.

29. F. A. Cotton, X. Feng, M. Matusz and R. Poli, J. Am. Chem. Soc, 1988, 110, 7077.

30. H. E. Abdou, A. A. Mohamed and J. John P. Fackler, Inorg. Chem., 2005, 44, 166.

31. J. P. Coyle, A. Kurek, P. J. Pallister, E. R. Sirianni, G. P. A. Yap and S. T. Barry, Chem. Commun., 2012, 48, 10440.

32. E. S. Beh, L. Tong and R. G. Gordon, Organometallics, 2017 36, 1453.

33. M.-C. Brandys, M. C. Jennings and R. J. Puddephatt, J. Chem. Soc., Dalton Trans., 2000, 0, 4601.

34. D. Fenske, G. Baum, A. Zinn and K. Dehnicke, Z. Naturforsch. $B, 1990,45,1273$.

35. A. A. Mohamed, A. P. Mayer, H. E. Abdou, M. D. Irwin, L. M. Pérez and J. John P. Fackler, Inorg. Chem., 2007, 46, 11165.

36. H. E. Abdou, A. A. Mohamed, J. M. López-de-Luzuriaga and J. John P. Fackler, J. Cluster Sci., 2004, 15, 397.

37. A. A. Mohamed, H. E. Abdou, M. D. Irwin, J. M. López-deLuzuriaga and J. John P. Fackler, J. Cluster Sci., 2003, 14, 253.

38. E. Hartmann and J. Strähle, Z. Naturforsch. B, 1989, 44, 1.

39. S. K. Adas, J. A. Ocana and S. D. Bunge, Aust. J. Chem., 2014, 67, 1021.

H. Schmidbaur, H. G. Raubenheimer and L. Dobrzanska, Chem. Soc. Rev., 2014, 43, 345.

S. Wang, N. Harmgarth, P. Leibing and F. T. Edelmann, Acta Cryst., 2016, E72, 1786.

M. D. Irwin, H. E. Abdou, A. A. Mohamed and J. John P. Fackler, Chem. Commun., 2003, 2882. 